\title{
Calorimetry and other methods in the studies of expansive cement hydrating mixtures
}

\author{
W. Nocuń-Wczelik $\cdot$ A. Bochenek $\cdot$ M. Migdał
}

Bretsznajder Special Chapter

(C) The Author(s) 2012. This article is published with open access at Springerlink.com

\begin{abstract}
In this study, the calorimeter was applied to follow the hydration of special cement mixtures exhibiting expansion or shrinkage compensation. The shrinkage-less and expansive binders were produced by mixing of Portland cement with an expansive additive produced by sintering and composed of calcium sulfoaluminate (yeelimite), calcium sulfate (anhydrite) and lime. The studies were focused on the synthesis of this aluminate-sulfatelime additive (temperature of burning process as a parameter controlling the relative activity of components) from the materials being the by products and subsequently on the mixture proportions to ensure the hydration process resulting in non-shrinkage or expansion effect. In the experiments the proportions of expansive mixture and cementitious materials were variable. The investigations with aim to find the relationship between the volume changes and composition of initial mixtures in cement pastes and mortars (with sand) were also carried out. The phase composition and microstructure of products were characterized. The expansive additive in the environment of hydrating cement transforms into ettringite and gives an increase of volume when the plastic material transforms to the more rigid matter but before the ultimate hardening takes place. Proper, moderate setting and hardening in strongly modified mixtures is achieved when the calorimetric curve corresponding to the heat evolution on hydration is analogous to that for the basic Portland cement. The rate of heat evolution data are well compatible with the other results related to the other methods of
\end{abstract}

W. Nocun-Wczelik $(\bowtie) \cdot$ A. Bochenek · M. Migdał Faculty of Material Science and Ceramics, University of Science and Technology-AGH, Al. Mickiewicza 30,

30-059 Kraków, Poland

e-mail: wiesia@agh.edu.pl hydration kinetics assessment (e.g. chemical shrinkage) and discussed in terms of the phase composition of hydration products.

Keywords Calcium sulfoaluminate - Portland cement . Heat of hydration $\cdot$ Ettringite $\cdot$ Expansion

\section{Introduction}

The kinetics and mechanism of hydration in various cementitious systems can be investigated by use of calorimetry [1-5]. The heat evolution curve reflects the rate of reactions occurring in the hydrating system and accompanying cement setting and hardening. Hydration of cement paste is a complex process, however, the heat evolution profile consists generally of the two peaks with the induction period between them and this can be observed only in case of binding materials in which the hydration reactions, structure formation and, finally, proper setting and strength development occur. Moreover, this method appears very useful as an auxiliary tool giving an overall continuous view on the hydration process not only at early age but also it is very helpful as the more practical parameters of hardened material should be predicted. The DTA/TG method has been commonly used for a long time to characterize the hydration products based on their dehydration curves on heating.

The standard cement pastes, mortars and concretes show generally less or more visible shrinkage on setting and hardening because the volume of formed hydrated phases is less than the volume of initial components. However, in some structures, mainly the underground ones, as well as in some repairing works the expansive or at least shrinkage compensation binders are needed. 
The expansive cements binders are usually produced by mixing of different Portland cements with an expansive additive composed of calcium sulfoaluminate components or the mixture of calcium aluminate cement and calcium sulfate (gypsum or anhydrite) [6, 7]. These additives in the environment of hydrating cement transform into ettringite- $3 \mathrm{CaO} \cdot \mathrm{Al}_{2} \mathrm{O}_{3} \cdot 3 \mathrm{CaSO}_{4} \cdot 3_{2} \mathrm{H}_{2} \mathrm{O}$ exhibiting a substantial increase of volume. An expansion of paste should be observed when the structure loses its plasticity but it is enough strong to bear the stresses attributed to the expanded crystalline ettringite. Among the three types of expansive cements classified the ASTM C845-04 standard [8] the high-calcium aluminate cement based one was the subject of our previous studies $[9,10]$. Our efforts focused previously on the synthesis of anhydrite-lime sinter to transform the monocalcium aluminate into ettringite. As a next step the synthesis of sinter containing three components, viz. the calcium sulfoaluminate (compound synthesized by Klein, corresponding to the natural mineral yeelimite), anhydrite and $\mathrm{CaO}$ of activity to produce ettringite during early hardening of cement paste/mortar was undertaken. The transformation of this expansive additive to ettringite can be written as follows:

$4 \mathrm{CaO} \cdot 3 \mathrm{Al}_{2} \mathrm{O}_{3} \cdot \mathrm{SO}_{3}+8 \mathrm{CaSO}_{4} \cdot 2 \mathrm{H}_{2} \mathrm{O}$

$+6 \mathrm{Ca}(\mathrm{OH})_{2}+74 \mathrm{H}_{2} \mathrm{O}$

$=3\left(3 \mathrm{CaO} \cdot \mathrm{Al}_{2} \mathrm{O}_{3} \cdot 3 \mathrm{CaSO}_{4} \cdot 32 \mathrm{H}_{2} \mathrm{O}\right)$

The kinetics of this reaction and the course of volume/ structure changes are strongly affected by the chemical activity and proportions of the $\mathrm{Al}_{2} \mathrm{O}_{3}$ and $\mathrm{CaO} \cdot \mathrm{SO}_{3}$ bearing compounds and the presence of $\mathrm{CaO}$ [11]. Not only the type and amount of aluminate proportioned into the Portland cement determine the rate and amount of ettringite formed at appropriate time to give the expansion but also the source of sulfate and calcium ions which provide an environment to stabilize the ettringite crystals [10-12]. Ettringite begins to form almost immediately after water is added to cement, however, it can hinder the dissolution of the other components when present as an impermeable layer on the surface of hydrating grains. On the other side, the calcium sulfoaluminate component should be completely synthesized and should exhibit a "hydration ability". The $\mathrm{CaO}$ component should be neither too active nor inactive (it depends on the temperature of calcium carbonate decomposition).

In this study the mixtures of cement with the sinter composed of calcium sulfoaluminate (yeelimite), anhydrite and calcium oxide, produced by heating at various temperatures in the range $1150-1250{ }^{\circ} \mathrm{C}$. The raw mixture to be sintered was proportioned (approximately) to give the ettringite phase; the additives were mixed with the commercial Portland cement to obtain an expansive binder. The expansion progress versus time was investigated, as well as the heat evolution process was followed. In the next series of DTA/TG measurements, the flexural strength determination and microscopic observations were carried out. The phase composition of hydrating pastes was studied by XRD.

\section{Experimental}

\section{Materials}

The standard Portland cement type CEM I $42 \mathrm{~N}$ commercially available was used as a basic component of expansive binders. The specific surface was approximately $3,200 \mathrm{~cm}^{2} / \mathrm{g}$ (as measured by Blaine method). The chemical composition is given in Table 1 .

The phase composition of Portland cement was as follows: Alite (tricalcium silicate)—64\%; Belite (dicalcium silicate)-17\%; tricalcium aluminate-8\%; Brownmillerite (tetracalcium aluminoferrite)—6\%, Gypsum-4\%.

The raw mixture for the tetracalcium sulfoaluminate, lime and calcium sulfate containing sinter $(70 \%$ yeelimite to $30 \%$ (anhydrite $+\mathrm{CaO}$ )) was proportioned using the desulfogypsum (containing approximately $95 \% \mathrm{CaSO}_{4} \cdot 2 \mathrm{H}_{2} \mathrm{O}$, that is $45 \% \mathrm{SO}_{3}$; source of calcium sulfate), limestone $(55 \% \mathrm{CaO})$ and bauxite $\left(71 \% \mathrm{Al}_{2} \mathrm{O}_{3}\right)$. The chemical com position of sinter is given in Table 2 .

The molar ratios between the calcium oxide, alumina and sulfur oxide in the sinter are approximately $6: 1: 3$, as in ettringite. After the homogenization (on grinding) the

Table 1 Composition of basic cement

\begin{tabular}{lllllllll}
\hline Component & $\mathrm{CaO}$ & $\mathrm{SiO}_{2}$ & $\mathrm{Al}_{2} \mathrm{O}_{3}$ & $\mathrm{Fe}_{2} \mathrm{O}_{3}$ & $\mathrm{MgO}$ & $\mathrm{SO}_{3}$ & Loss on ignition \\
\hline Percentage (wt $\%)$ & 66.0 & 23.0 & 4.7 & 2.4 & 1.2 & 1.2 & 0.1 \\
\hline
\end{tabular}

Table 2 Composition of expansive component

\begin{tabular}{lllllllll}
\hline Component & $\mathrm{CaO}$ & $\mathrm{Al}_{2} \mathrm{O}_{3}$ & $\mathrm{SO}_{3}$ & $\mathrm{SiO}_{2}$ & $\mathrm{Fe}_{2} \mathrm{O}_{3}$ & $\mathrm{MgO}$ & $\mathrm{TiO}_{2}$ & $\mathrm{Total}$ \\
\hline Percentage (wt\%) & 50.1 & 13.4 & 31.3 & 1.4 & 2.3 & 0.4 & 0.6 & 99.5 \\
\hline
\end{tabular}


heating of the raw mixture samples at $1150,1200,1250$ and $1180{ }^{\circ} \mathrm{C}$ was done. After cooling the sinters were subjected to grinding to produce a fine powder (with the specific surface $3,200 \mathrm{~cm}^{2} / \mathrm{g}$ approximately, as measured by Blaine method). The abbreviations for the type of expansive additive include the "CSA" (here: $\mathrm{C}=\mathrm{CaO}$, $\mathrm{S}=\mathrm{SO}_{3}$ and $\mathrm{A}=\mathrm{Al}_{2} \mathrm{O}_{3}$ ) and temperature; therefore we have CSA 1150, CSA 1180, CSA1200, 1250 CSA.

In the basic series of experiments the mixture was added as a 8 and $15 \%$ cement replacement; the dosage of additive was fixed basing upon the former experiments $[9,10]$. In some experiments the hydrating pastes were produced using the 2, $412 \%$ additive. The expansive mixture without Portland cement was also examined, as well as the basic cement (reference).

\section{Methods}

Basing on our previous experiences with expansive materials we firstly prepared the glass vessels with expansive binders, as for XRD and DTA/TG studies; the best expansion (earliest damage of vessels) was found for the mixtures of cements with CSA 1,200 and 1,150; therefore we decided to produce a sinter at "mean" temperature$1,180{ }^{\circ} \mathrm{C}$. The possibility to lower the temperature of synthesis is important from the energy saving and further practical implementation of our results.

The partially restrained expansion of cement-expansive additive blends was tested using a special equipment - the horizontal moulds playing the role of restraining cage with one moving endplate touching the measuring screw. The changes of position were transferred through the sensor of movement to the data logger linked with computer. In such a way the continuous measurements were possible. The pastes prepared at water to solid ratio 0.40 (w/s; lowered from standard 0.5 to avoid bleeding), mixed in special blender to counteract the early stiffening, were placed in the moulds and covered with thin polyethylene foil. The moulds with pastes were stored at constant temperature $23 \pm 2{ }^{\circ} \mathrm{C}$.

The nonisothermal-nonadiabatic differential microcalorimeter was used to follow the heat evolution on hydration (modified BMR differential microcalorimeter from the Institute of Physical Chemistry, Polish Academy of Science in Warsaw). Hydrating pastes were prepared by mixing of $5 \mathrm{~g}$ samples with $2.5 \mathrm{ml}$ of water (water to solid ratio 0.5 ; as in many standard measurements for cements); the initial temperature was kept constant at $25{ }^{\circ} \mathrm{C}$. The heat evolved values were measured with accuracy of $\pm 5 \mathrm{~J} / \mathrm{g}$.

The phase composition of selected hydrating pastes was characterized by XRD (Philips diffractometer) and DTA/TG measurements (Derivatograph Q1500 D; mass of samples$700 \mathrm{mg}$, heating rate $10^{\circ} \mathrm{C} / \mathrm{min}$, in air). In order to produce the specimens for XRD and DTA/TG studies the pastes hydrating for 1,2 or 3 days at water to solid ratio 0.5 were finely crushed, washed several times with acetone and carefully dried with cold air to remove the free water (to stop further hydration). The mortars with the following composition: cement (with or without relevant cement replacement $-450 \mathrm{~g}$, standard quartz sand- $-1350 \mathrm{~g}$, water -200 $\mathrm{ml}$ were prepared, cured in standard conditions [13] and subjected to the strength measurements. The fractured hydrated samples (3-day hydration), were examined under SEM.

\section{Results}

The calorimetric results, expansion measurements, XRD studies for samples containing the additives synthesized at different give the similar sets of figures; that is why only the examples are given.

The plot illustrating the expansion of pastes versus time is shown in Fig. 1. The heat evolution curves (selected examples) are shown in Figs. 2, 3 and 4. The example sets of diffraction patterns for hydrating cement mixtures and hydrating expansive additive are shown as Figs. 5, 6 and 7 . The development of flexural strength on bending is shown in Fig. 8. The example microstructures of fractured 3-day hydrated samples are presented in Fig. 9 and finally, the samples with no unbound water, removed to stop further hydration, were subjected to the DTA/TG measurements. Their results are presented in Fig. 10 and in Table 3.

\section{Discussion}

Though all the sinters had similar impact on the volume changes when added to Portland cement, a little better expansion was found for the tetracalcium sulfoaluminate, lime and calcium sulfate containing sinter synthesized at

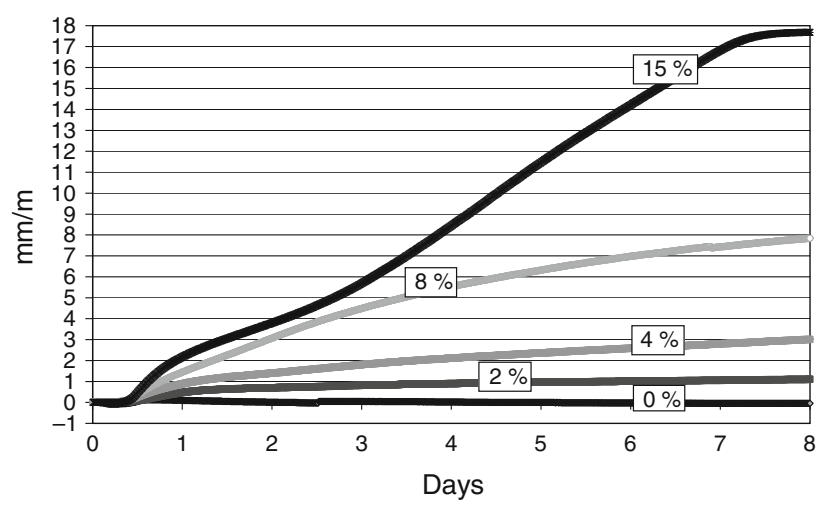

Fig. 1 Restrained expansion of pastes versus time, growing with the percentage of expansive mixture (CSA 1180) 


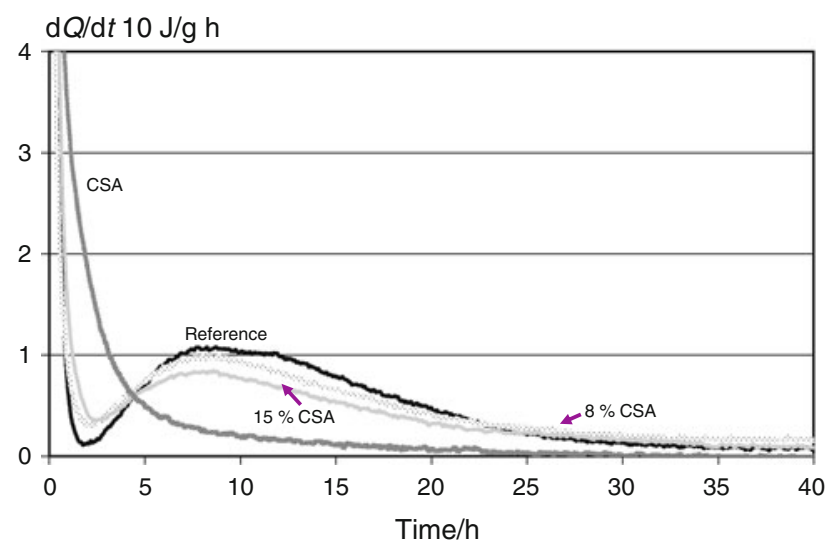

Fig. 2 Rate of heat evolution curves for the CSA 1200 additive and expansive cements with $8-15 \% \mathrm{CSA}$; w/s $=0.50$

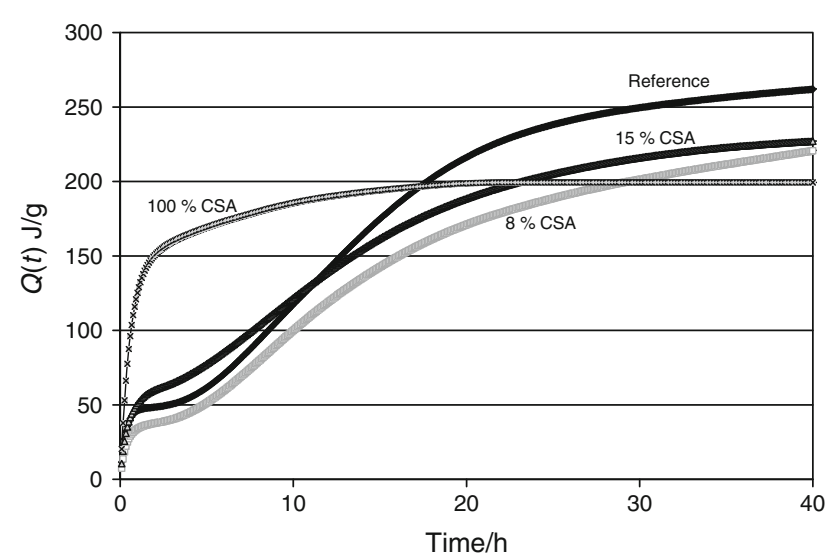

Fig. 3 Heat evolved values for the CSA 1180 additive and expansive cements with $8-15 \% \mathrm{CSA} ; \mathrm{w} / \mathrm{s}=0.50$

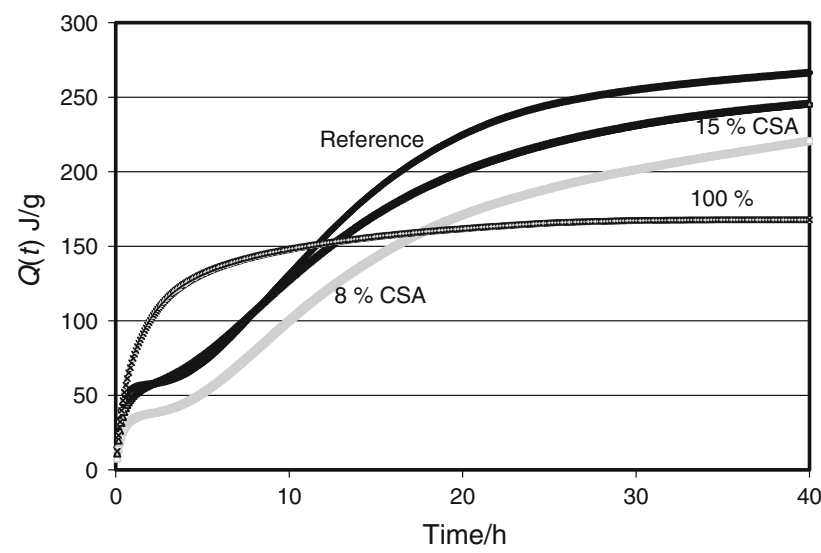

Fig. 4 Heat evolved values for the CSA 1250 additive and expansive cements with $8-15 \% \mathrm{CSA} ; \mathrm{w} / \mathrm{s}=0.50$

$1180{ }^{\circ} \mathrm{C}$. This series of samples was subjected to more detailed studies. As one could expect the expansion depends upon the amount of expansive additive (Fig. 1). The small linear changes slightly exceeding 1 and $3 \mathrm{~mm} / \mathrm{m}$

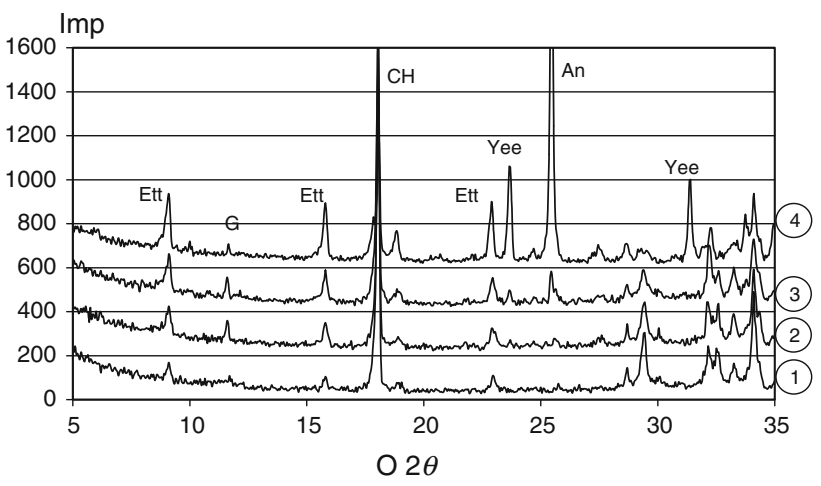

Fig. 5 XRD. Phase composition of pastes after 2-day hydration, for the reference cement (1), cement with $8 \%$ CSA 1200 (2), cement with $15 \%$ CSA 1200 (3) and CSA 1200 expansive additive (4); w/s $=0.50$

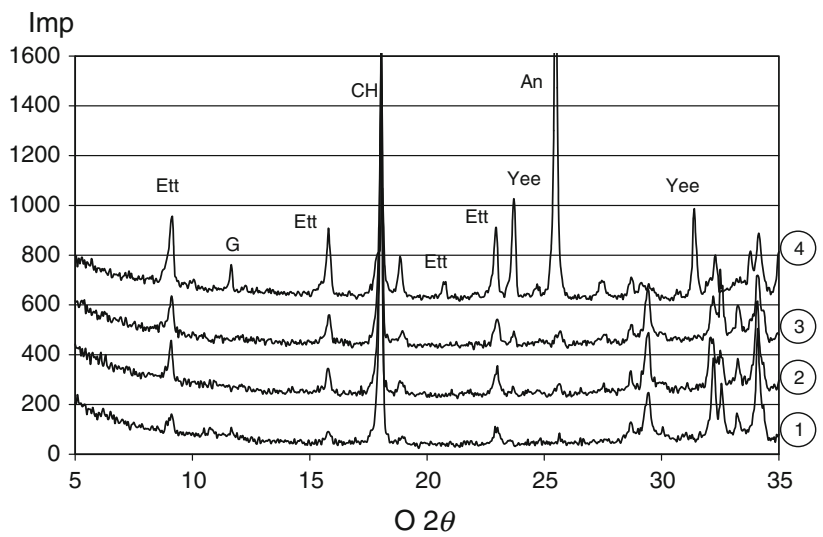

Fig. 6 XRD. Phase composition of pastes after 3-day hydration, for the reference cement (1), cement with $8 \%$ CSA 1200 (2), cement with $15 \%$ CSA $1200(3)$ and CSA 1200 expansive additive (4); w/s $=0.50$

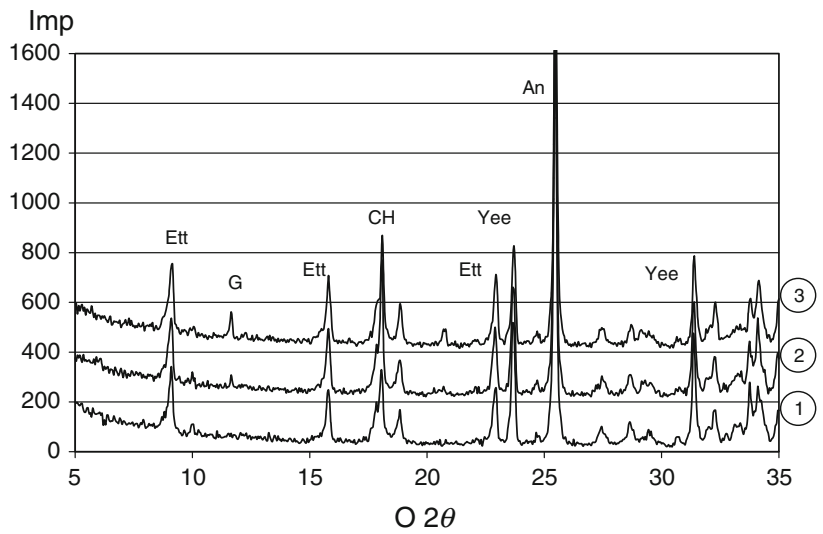

Fig. 7 XRD. Phase composition of pastes produced from expansive additive CSA 1200 hydrated 1-day (1), 2 days (2) and 3 days (3); $\mathrm{w} / \mathrm{s}=0.50$

( 0.1 and $0.3 \%$, respectively) were found for the 2 and $4 \%$ CSA content (these binders can be considered as a shrinkage compensating ones), while for $8 \%$ CSA the paste revealed $7 \mathrm{~mm} / \mathrm{m}(0.7 \%)$ length growth. At higher 


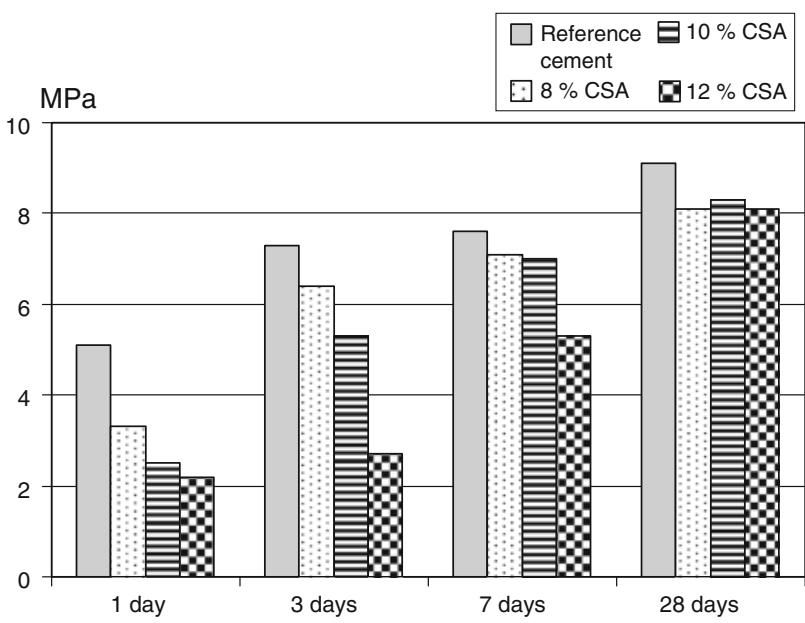

Fig. 8 Flexural strength of standard expansive cement mortars (CSA 1180) after 1, 3, 7 and 28-day hardening content $(15 \%)$ of expansive additive the length increase was $17 \mathrm{~mm} / \mathrm{m}(1.7 \%)$ and this value seems to be too high to avoid some microcracks and lowered durability. The results comply with the range of linear changes attributed, in the ASTM 845-04 standard, to the shrinkage compensation and expansive material (though the composition of sample and measuring mould decline from that recommended in ASTM). Expansion commences 1 day after mixing of cementitious material with water and the most evident, steady growth takes place during the first 3-4 days, however, except of the sample with $15 \%$ CSA. It means that the ettringite formation occurs at moderate rate and it is not limited by setting process and precipitation of the other hydration products. The volume increase becomes slower and slower during the next 5-7 days from the beginning of the processing with water and then it stabilizes.
Fig. 9 SEM. Microstructure of hardened expansive cement samples with $8 \%$ CSA 1180 additive (left) and $15 \%$ CSA 1180 additive (right) after 3-day hydration. See the elongated ettringite forms
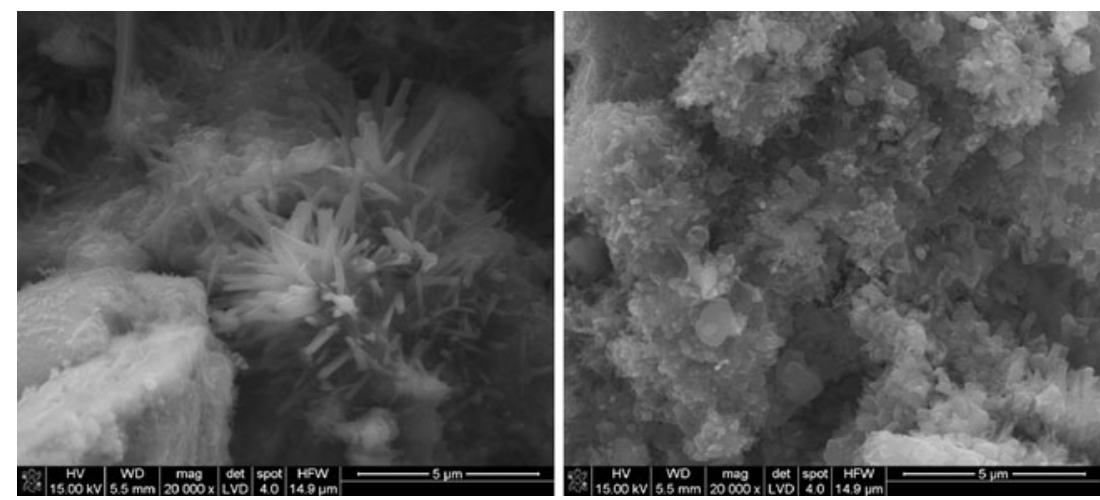

Fig. 10 DTA curves of hydrated reference cement, expansive cements and expansive additive (CSA 1200)
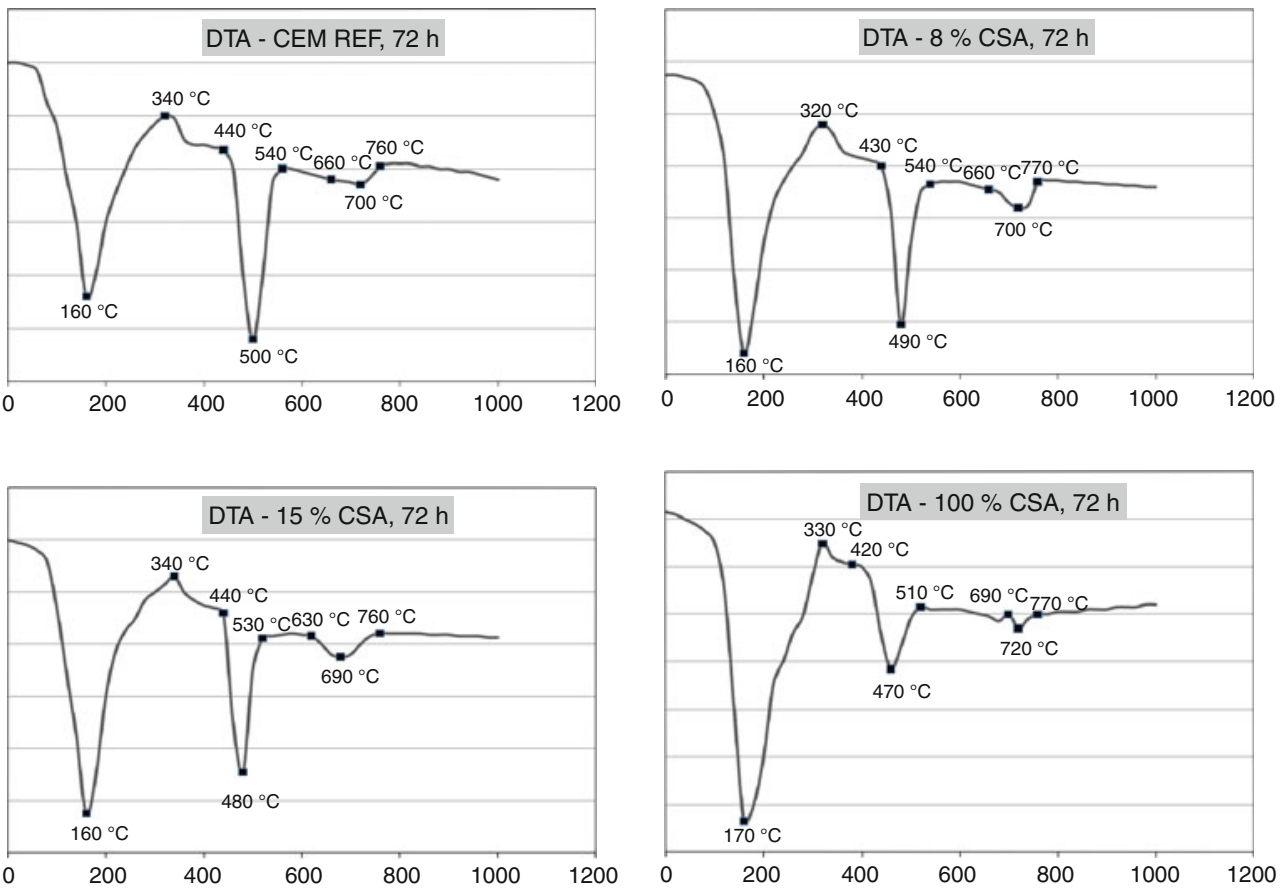
Table 3 TG-measurements: loss of mass and estimated contents of calcium hydroxide based upon the TG data (CSA 1200)

\begin{tabular}{|c|c|c|c|c|}
\hline \multirow[t]{2}{*}{ Sample } & \multicolumn{2}{|l|}{ After $48 \mathrm{~h}$} & \multicolumn{2}{|l|}{ After $72 \mathrm{~h}$} \\
\hline & $\begin{array}{l}\mathrm{H}_{2} \mathrm{O} \text { in ettringite } \\
\text { and } \mathrm{C}-\mathrm{S}-\mathrm{H}(\mathrm{wt} \%)\end{array}$ & $\mathrm{Ca}(\mathrm{OH})_{2}(\mathrm{wt} \%)$ & $\begin{array}{l}\mathrm{H}_{2} \mathrm{O} \text { in ettringite } \\
\text { and } \mathrm{C}-\mathrm{S}-\mathrm{H}(\mathrm{wt} \%)\end{array}$ & $\mathrm{Ca}(\mathrm{OH})_{2}(\mathrm{wt} \%)$ \\
\hline Reference cement & 12.0 & 13.6 & 13.3 & 12.3 \\
\hline $100 \%$ CSA & 13.0 & 8.9 & 14.3 & 8.2 \\
\hline $15 \%$ CSA & 14.3 & 12.3 & 13.7 & 11.7 \\
\hline $8 \% \mathrm{CSA}$ & 14.0 & 12.0 & 14.3 & 12.3 \\
\hline
\end{tabular}

The calorimetric curves for those samples which exhibit proper "standard" expansion do not decline specially from the commonly known heat evolution plots for Portland cement (Fig. 2). Obviously, they reflect some shortage of "basic" cement, however, the formation of some more ettringite, being highly exothermic (high, broadened first peak, shorter induction period, lower second peak) is proved. The amount of ettringite seems not to be too high at the beginning and during the induction period, however, it is sufficient to produce the effect of shrinkage compensation or expansion as it is observed (Fig. 1). Further ettringite formation coincides well with the formation of the other hydration products, after the induction period. This can be noticed on the $Q(t)=f(t)$ curves (Figs. 3, 4) where the line for the sample with $15 \% \mathrm{CSA}$ is situated above that for the sample with $8 \%$ CSA. One can see that the hydration of CSA itself is accompanied by a rapid heat evolution in a form of one single $\mathrm{d} Q / \mathrm{d} t$ peak (Fig. 2) and that the reaction of CSA 1180 with water goes with better effectiveness (steady growth over longer period of time, high $Q$ value) than the hydration of CSA 1150, 1200 and 1250; the latter one plotted as an example (see Figs. 3, 4). Presumably the better activity of particular components in the CSA 1180 allows to produce more ettringite without disturbing the dissolution of initial material. The ettringite is known as forming an impermeable layer during the early cement hydration; however, the diffusion of water through the impermeable layer of hydrates results in swelling of hydrated calcium silicates from Portland cement component and this barrier collapses after a time.

The XRD plots showing the phase composition of pastes after 2 or 3 days of hydration with different percentage of additives are presented as Figs. 5 and 6. The ettringite phase is present in all the samples and the differences of intensity between the peaks attributed to ettringite both in reference cement and $100 \%$ CSA seem not to be very impressive. This would suggest the presence of the layer of hydration products (basically ettringite) surrounding the hydrating grains and hampering the dissolution of initial unhydrous phases. The amount of ettringite is slightly growing with the percentage of expansive component, there is also some anhydrite residue (visible mainly in the sample with $100 \%$ expansive mixture), some gypsum (product of anhydrite hydration) and $\mathrm{Ca}(\mathrm{OH})_{2}$. The latter phase originates both from $\mathrm{CaO}$ and calcium silicates (main constituents of Portland cement) hydration. The peaks in the range $29^{\circ} \div 35^{\circ} 2 \theta$ are attributed to the residue of anhydrous cement phases (calcium silicates) and become lower with time. It means that the hydration of Portland cement constituents is continued. Obviously, in the hydrated samples of $100 \%$ CSA additive (Fig. 7) the ettringite is somewhat better visible together with the residue of anhydrite and yeelimite phase. The anhydrite phase seems to play a role of the sulfate anions source-it enters the solution to form ettringite; a small amount of gypsum from anhydrite hydration appears at later age.

The flexural strength of mortars with cement replacement is, as one could expect, lower than the value for reference, proportionally to the CSA percentage (Fig. 8), particularly after 1 or 3 days. However, the relative differences reduce with time and become negligible for variable CSA content. The hardened material is undoubtedly strengthened-the 7 and 28-day flexural strength data prove also the formation of fibrous ettringite component modifying the structure of hardened cement composite.

The presence of ettringite is clearly seen in the SEM micrographs (Fig. 9). This is a dominating component of hydrated paste, located together with calcium silicate hydrate in its weakest part exposed after crushing before SEM specimens preparation.

There are three peaks on the DTA curves (Fig. 10) - the first one in the range up to approximately $350{ }^{\circ} \mathrm{C}$ (dehydration of ettringite, gypsum, calcium silicate hydrate), the second one with the maximum about $480{ }^{\circ} \mathrm{C}$ (dehydration of calcium hydroxide) and a peak(s) in the temperature range from 650 to $750{ }^{\circ} \mathrm{C}$ (the reaction between the dehydration products: aluminium oxide, calcium oxide, silica, visible for $100 \% \mathrm{CSA}$, as well as the decomposition of some carbonated $\mathrm{CaO}$ ). One can notice the similarity between the course of DTA curves both for reference cement and cement with additive, as well as for $100 \%$ calcium sulfoaluminateanhydrite-lime sinter. In case of CSA component, where 
there is no calcium silicate from cement, the presence of $\mathrm{Ca}(\mathrm{OH})_{2}$ can be attributed only to the hydration of $\mathrm{CaO}$.

The TG data (Table 3) for hydrating expansive binder and expansive sinter only were used to evaluate the content of ettringite. Taking into account the calcium hydroxide content and assuming that the rest of $\mathrm{CaO}$ entered the ettringite phase, the approximate percentage of initial additive material combined to form ettringite was evaluated for ca. $60 \%$ after 2 days. The similar or a little higher ettringite content is presumably present after 3-day hydration of CSA sinter, as one could conclude from the XRD data (Fig. 7). Considering the XRD results (the intensity of XRD peaks corresponding to this phase) for cement with expansive component produced pastes one can conclude that the effectiveness of "additional" ettringite formation in these hydrating mixtures is rather high, as the contents of ettringite forming compounds and are taken into account.

\section{Conclusions}

- Heat evolution at the presence of expansive mixture giving the controlled shrinkage compensation or expansion effect, corresponding to ettringite, is well compatible with the heat evolution for matrix cement. The heat evolved value is the highest for the most effective calcium sulfoaluminate additive CSA $1180{ }^{\circ} \mathrm{C}$.

- The mixtures composed of the Portland cement and the calcium sulfoaluminate-lime-anhydrite sinter play successfully the role of shrinkage compensation or expansive material. The mixtures added as ca. 2 or $4 \%$ Portland cement replacement give a slight expansive effect; at the 8 or $15 \%$ cement replacement-the controlled expansion occurs. The volume changes are markedly reduced after the first 3-4 days, particularly at low expansive additive content.

- The hydration products formed in cement paste with expansive mixture are: ettringite, calcium hydroxide and calcium silicate hydrate and gypsum. The early hydration is controlled by the formation of ettringite; the amount of this phase stabilizes after 3-day hydration; further growth of hydration products is slowed down. This situation, however, can have a beneficial impact on the development of some practical properties (strength, durability).
Acknowledgements The financial support from the Ministry of Science and Education in Poland (Grant no. N N507 450934) is acknowledged.

Open Access This article is distributed under the terms of the Creative Commons Attribution License which permits any use, distribution, and reproduction in any medium, provided the original author(s) and the source are credited.

\section{References}

1. Pacewska B, Błonkowski G, Wilińska I. Studies on the pozzolanic and hydraulic properties of fly ashes in model systems. J Therm Anal Cal. 2008;94:469.

2. Talero R, Rahhal V. Calorimetric comparison of portland cements containing silica fume and metakaolin. Is silica fume, like metakaolin, characterized by pozzolanic activity that is more specific than generic. J Therm Anal Calorim. 2009;96:383.

3. Wu ZB, Guan BH, Lou WB, Ye QQ, Fu HL. Calorimetric study of calcium aluminate cement blended with flue gas desulfurization gypsum. J Therm Anal Calorim. 2009;98(3):737-42.

4. Gruyaert E, Robeyst N, De Belie N. Study of the hydration of Portland cement blended with blast-furnace slag by calorimetry and thermogravimetry. J Therm Anal Calorim. 2010;102(3): 941-51.

5. Linglin X, Peiming W and Guofang Z. Calorimetric study on the influence of calcium sulfate on the hydration of Portland cementcalcium aluminate cement mixtures. J Therm Anal Calorim. 2011. doi:10.1007/s10973-011-1920-z.

6. Odler I. Special inorganic cements. London: Taylor \& Francis; 2000. p. 316

7. Mehta PK, Polivka M. Expansive cements. In: Proceedings of the Sixth International Congress on the Chemistry of Cement, vol 3, Moscow. 1974. p. 158.

8. ASTM C845. Standard specification for expansive hydraulic cement. West Conshohocken: ASTM International; 2004.

9. Konik Z, Małolepszy J, Roszczynialski W, Stok A. Production of expansive additive to portland cement. J Eur Ceram Soc. 2007; 27:605.

10. Nocun-Wczelik W, Konik Z, Stok A. Blended systems with calcium aluminate and calcium sulphate expansive additives. Con Build Mat. 2011;25:939.

11. Szelagg H. Factors governing the stresses appearing in the mortars of expansive cement. Part 1 and 2. Cement Wapno Beton 2008; 13/75:315. 2009;14/76:11.

12. Kurdowski W. Chemistry of Cement. In: Warsaw PWN, editor. 1991. p. 415 (in Polish).

13. EN-PN 197-1:2002, Cement: composition. Requirements and conformity criteria for common cements. 2002. 